\title{
Dentists call for action as figures show full impact of pandemic on service in
}

\section{Northern Ireland}

$\mathrm{T}$ he British Dental Association Northern Ireland has said further action is needed to ensure Health Service dentistry can recover from the impact of the COVID19 pandemic as new figures reveal the full extent of the collapse in attendance.

The General Dental Services Statistics for 2020/21 show the volumes of dentistry delivered since April 2020 were less than a third of usual levels, with over 3 million fewer treatments delivered to adults and children. Just $40 \%$ of patients were seen compared to the previous year, with over 440,000 fewer adults and nearly 70,000 fewer children.

Dentistry has been hit by the imposition of strict new infection prevention control measures such as enhanced PPE, social distancing measures, and extra cleaning and 'fallow time' - mandated gaps between patients - which have impacted considerably on the ability to see patients, with activity still reduced to around $40 \%$ of pre-COVID- 19 levels.

Oral health inequality is set to widen as a result of the COVID-19 pandemic, given the ongoing disruption to dental services, the suspension of public health programmes, and the impact of lockdown diets. Northern Ireland has traditionally been at the bottom of the UK league table for oral health, with just under a fifth (19\%) of 15-year-old children in Northern Ireland considered to have good oral health overall. With an election potentially looming, dentists are calling on all parties to pledge to deliver a three-pronged approach to guarantee that Health Service dentistry in Northern Ireland can survive the impact of the pandemic: $\rightarrow$ A new Oral Health Strategy aimed at delivering improved outcomes for the population and reducing oral health inequalities

$\rightarrow$ Work to begin on a new General Dental Services (GDS) contract to safeguard a future for Health Service dentistry

$\rightarrow$ Provide needed capacity at the Department of Health to be able to progress the major reforms needed in dentistry.

The BDA has long advocated a root and branch overhaul of Northern Ireland's oral health strategy which is now over 14 years old. It says a new policy must run in parallel with reforming the decades old activitybased contract that Health Service Dentistry is based on, which is simply unworkable post-COVID-19. The change of emphasis being called for is to move away from 'counting widgets' to a model that recognises and rewards work improving the oral health of the population.
The profession has acknowledged the short-term support provided to dentists under Financial Support arrangements over the past year, and the Minister's recent confirmation that a new GDS Rebuilding Stakeholder Group will be established to help tackle these issues and that limited administrative capacity in $\mathrm{DoH}$ will be reviewed.

Richard Graham, Chair of the British Dental Association's Northern Ireland Dental Practice Committee said: 'With an election possibly just months away, these figures underline why dentistry must be on every party's agenda.

'A service long teetering is now broken and will require nothing less than a full rebuild if it's ever going to meet demand from the hundreds of thousands who have missed out on needed care. Morale across the profession has collapsed. Things were barely sustainable pre-COVID-19, and now many colleagues simply cannot see a future providing Health Service dentistry.

'There is much work to do to ensure access to Health Service dentistry can be sustainable going forward, and we urge every party that values it commit to taking that work forward in earnest. Our message to every MLA, candidate, and party is simple: it is high time to give oral health the priority it desperately needs.'

\section{Dentists call for real effort to push junk food brands out of sport}

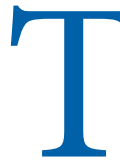

he British Dental Association has welcomed leadership from footballer Ronaldo, in shunning UEFA Euro 2020 sponsor Coca-

Cola, but warned that sustained effort is required UK and worldwide to remove the deep-rooted and pernicious influence of junk food brands across sport.

The captain of the Portuguese national team has promoted KFC - together with its partner brand Pepsi - while his Italian Serie A Club Juventus receives funding from both Coca-Cola and M\&Ms.

Dentists are deeply concerned that oral health inequality among children will widen as a consequence of the COVID-19 pandemic, as a result of unhealthy lockdown diets, limited access to services, and the suspension of public health programmes.

The BDA believes the Government should apply the same logic to junk food sponsorship, as has been previously applied to alcohol, tobacco, and gambling. While there are moves to ban junk food advertising in primetime, sports sponsorship appears to offer a get-out clause.

Dentists have previously warned that even diet versions of fizzy drinks are more acidic than lemon juice or vinegar, and are helping to fuel an epidemic of dental erosion. This summer's Tokyo games will be the first Olympics in over 40 years not sponsored by burger giant McDonalds. BDA Chair Eddie Crouch said: 'Tooth decay affects close to 3.5 billion people worldwide. Yes, water is the right choice, but the influence of the junk food industry runs deep.

'We have a player sponsored by KFC, playing for a team funded by M\&Ms and Coca Cola itself. Sporting heroes provide wall-to-wall marketing for brands that actively undermine the oral health and overall health of consumers. As dentists, we know that no amount of exercise will protect against tooth decay.

'If ministers are serious about taking junk food advertising off the menu for children, they cannot leave sport untouched.' 